\title{
An Accurate Taylors Series Solution with High Radius of Convergence for the Blasius Function and Parameters of Asymptotic Variation
}

\author{
S.Anil Lal ${ }^{1}$ and Neeraj Paul M${ }^{2}$ \\ Department of Mechanical Engineering, \\ College of Engineering Trivandrum, Kerala, India \\ $\dagger$ Corresponding Author Email: anillal65@hotmail.com
}

(Received July, 18, 2013; accepted November, 08, 2013)

\begin{abstract}
This paper reports a high accurate solution of the Blasius function $f(\eta)$ in the form of a converging Taylor's series for a higher range of $\eta \in[0,9]$. The method used consists of conversion of the boundary value problem into an initial value problem and solution by differential transform method. The initial value of the second derivative of the Blasius function is determined from the final value of first derivative of another function. The final value of first derivative of the latter function is determined by the Taylor's series expansions with center at $\eta=15$. The series expansion for the Blasius function is obtained with center of expansion at $\eta=4$, is alternating and is accurately converging for higher values of $\eta$, with the number of used for summation equal to 2000 . The present expansion is obtained without resorting to approximations and has a higher radius of convergence. The first 200 coefficients of the series, the second derivative of the function at $\eta=0$, the parameters of the asymptotic solution are reported with 21 decimal places accuracy. The level of accuracy of the results presented is higher than any other results reported so far. This note also reports the mathematical steps involved in the derivation of the similarity variable of Blasius problem.
\end{abstract}

Keywords: Differential transform, Taylor's series, Similarity variable, Blasius function, Exact solution

\section{INTRODUCTION}

Ever since the formulation and solution of the function defined by $f^{\prime \prime \prime}(\eta)+\frac{1}{2} f(\eta) f^{\prime \prime}(\eta)=0$, with $f(0)=f^{\prime}(0)=0, f^{\prime}(\infty)=1$ and $\eta \in[0, \infty]$ by Blasius (1908), more than a century ago, the function called as Blasius function has been a subject of great interest to Mathematicians and Physicists (K.Toepfer and H.Blasius. (1912), Howarth (1938), Cortell (2005), Boyd (2008), Zaimi, Bidin, Bakar, and Hamid (2012)), to name a few. These investigations considered analytical as well as numerical methods for the solution of $f(\eta)$. Though the problem has been approximately solved using numerical techniques, difficulties encounter when the exact solution of the function is sought. This is mainly due to the fact that the exact solution is a power series without having a closed form and singularity of the function. A systematic investigation of the simple pole of the function and convergence behavior is reported by Boyd (1999). While a certain minimum number of terms are required to be summed for getting the results with required accu-

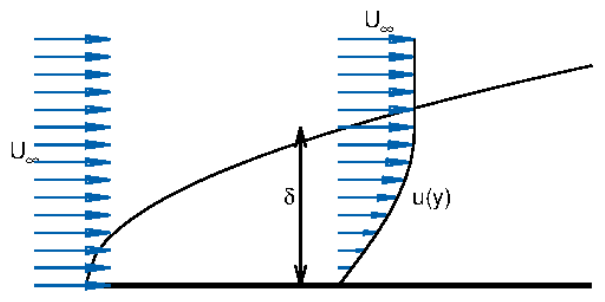

Fig. 1. Boundary Layer over a Flat plate.

racy levels, the solution for $\eta \gg 1$ is subjected to convergence problems. The present work explores the potential of differential transform method for solving non-linear initial value problems of functions with singularity. In order to obtain a higher radius of convergence of the series expansion of functions with singularity, shifting of the center of expansion is proposed. A new methodology consisting of recursive application of differential transform method for shifting the center of the expansion has been demonstrated. Hence a high accurate solution of Blasius function in the form of a con- 
verging power series with center of expansion at $\eta=4$ and a higher radius of convergence $\eta \in[0,9]$ than other results reported so far is obtained. The important parameters of the asymptotic solution are reported with a higher level of accuracy. This technical brief reports the method for converting the boundary value problem into an initial value problem. The first part of this note describes a systematic method for deriving the similarity variable for transforming the PDE of boundary layer equation into the Blasius equation.

\section{BOUNDARY LAYER OVER A FLAT PLATE}

Figure 1 shows a schematic diagram of boundary layer over a flat plate. It is a zero pressure gradient flow as the potential flow velocity is a constant and equal to the free stream velocity $U_{\infty}$. Thus the governing partial differential equation of boundary layer flow over a flat plate is written by neglecting the pressure gradient term in the Prandtl boundary layer equation as:

continuity $: \frac{\partial u}{\partial x}+\frac{\partial v}{\partial y}$

X-momentum : $u \frac{\partial u}{\partial x}+v \frac{\partial u}{\partial y}=v \frac{\partial^{2} u}{\partial y^{2}}$

The boundary conditions are $u=v=\frac{\partial^{2} u}{\partial y^{2}}=0$ at $y=0$ and $\frac{\partial u}{\partial y}=0$ at $y=\infty$.

The velocity $u$ in the boundary layer is a function of $x$ and $y$ coordinates. Typical velocity profiles as a function of $y$ drawn for different values of $x$ are shown in Fig. 2(a). A dimensionless variable $\eta$ formed by combining the independent variables $x, y$ and the physical constants of the problem such that variation of the non-dimensional velocity $u / U_{\infty}$ as a function of $\eta$ is a single curve as shown in Fig. 2(b) is called a similarity variable. Blasius (1908) defined the similarity variable as $\eta=y / \delta$ using physical arguments based on momentum transport. Cengel (2006) noted that finding of such a variable, assuming it exists, is more of an art than science, and it requires to have a good insight of the problem. But from a mathematical point of view, similarity variable can be visualized as a change of variable for a possible transformation of a PDE into an ODE. The first part of this note illustrates a systematic method for deriving the similarity variable for flat plate boundary layer from a mathematical point of view. A fundamental choice for combining $x, y$ and the physical constants may be to write $\eta=k A(x) B(y)$, where $k$ is related to the physical

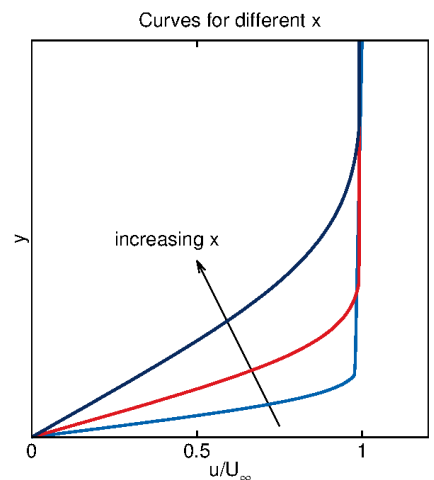

(a)

Single curve for any $x$ and $y$ in terms of $\eta$

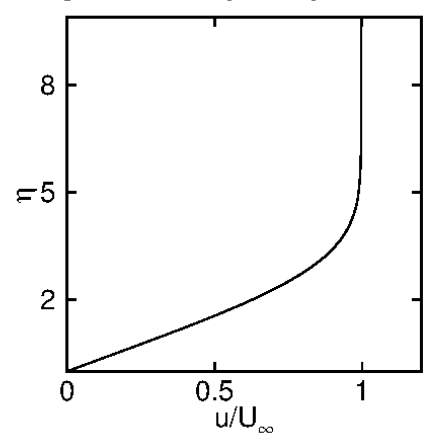

(b)

Fig. 2. Boundary Layer.

constants such as $v$ and $U_{\infty}$. By noting that all boundary conditions of the problem are based on the values of $y$, a convenient choice for $B(y)$ is taken as the variable $y$ itself. Thus,

$\eta=k A(x) y \quad$ with, $\frac{\partial \eta}{\partial x}=k y A^{\prime} \quad$ and $\quad \frac{\partial \eta}{\partial y}=k A$

The equation of the dimensionless velocity as shown in Fig. 2(b) has the form

$\frac{u}{U_{\infty}}=f^{\prime}(\eta)$ or $\quad u=U_{\infty} f^{\prime}(\eta)$

It is possible to satisfy the continuity Eq. (1) by deriving the velocity components from stream function $\psi(x, y)$ as

$u=U_{\infty} f^{\prime}(\eta)=\frac{\partial \psi}{\partial y} \Rightarrow \psi=\frac{U_{\infty} f}{k A}$

$v=-\frac{\partial \psi}{\partial x}=-\frac{U_{\infty}}{k}\left[\frac{A f^{\prime} k A^{\prime} y-f A^{\prime}}{A^{2}}\right]$

The other derivatives $u$ are

$$
\frac{\partial u}{\partial x}=U_{\infty} f^{\prime \prime} k A^{\prime} y, \quad \frac{\partial u}{\partial y}=U_{\infty} f^{\prime \prime} k A
$$

and

$\frac{\partial^{2} u}{\partial y^{2}}=U_{\infty} k^{2} A^{2} f^{\prime \prime \prime}$ 
Putting Eq. (5-7) in Eq. (2), it is possible to write

$f^{\prime \prime \prime}-\frac{U_{\infty} A^{\prime}}{v k^{2} A^{3}} f f^{\prime \prime}=0$

The condition for the above differential equation to represent an ODE is that, $\frac{U_{\infty} A^{\prime}}{v k^{2} A^{3}}$ is a constant.

$$
\begin{gathered}
\text { Taking } \frac{U_{\infty} A^{\prime}}{v k^{2} A^{3}}=-p,(p \text { is a constant }) \\
\Rightarrow A^{-3} \frac{d A}{d x}=-\frac{p v k^{2}}{U_{\infty}} \\
\text { (On integration) } \Rightarrow \frac{1}{A^{2}}=\frac{2 p v k^{2} x}{U_{\infty}} \\
\Rightarrow A^{2} k^{2}=\frac{U_{\infty}}{2 p v x}
\end{gathered}
$$

Since $p$ can have any arbitrary constant value, a choice that turns the expression of $A k$ to a compact form is $p=1 / 2$. Thus, the final expressions for $A k$ and $\eta$ become

$k A(x)=\sqrt{\frac{U_{\infty}}{v x}}$ and $\eta=y \sqrt{\frac{U_{\infty}}{v x}}$

The resulting ODE from Eq. (8) is called the Blasius equation

$f^{\prime \prime \prime}+\frac{1}{2} f f^{\prime \prime}=0 ; f(0)=f^{\prime}(0)=0$ and $f^{\prime}(\infty)=1(11)$

Presented in this section is a straight forward mathematical method for the derivation of similarity variable, for converting a PDE into an ODE. This method is based on mathematical concepts and the application of physics, intuitive judgments and experience are minimum. Existence or suitability of a similarity variable can be judged during the process of transformation.

The following sections consider conversion of the above boundary value problem into an initial value problem and subsequently solution by considering the singularity point of the function, $f(\eta)$. The potential of differential transform Zhou (1986) method is explored to derive accurate solution of the function with a higher radius of convergence.

\section{Converting Boundary VAlue Problem (BVP) to Initial Value Problem (IVP)}

Blasius problem is a non-linear, third order BVP. Solution of a non-linear BVP is complex, either involving iterative techniques or system of equations along with the use of a numerical technique. At the same time, Initial Value Problems can be solved easily. An important property of Blasius equation (11) is that it is satisfied by $a f(a \eta)$ also, which is a scaled variant of $f(\eta)$, where $a$ is a scaling constant. This property called dilational or scaled symmetry of Blasius equation is first observed by Toepfier[2], and this property of the function can be applied to determine the value of $f^{\prime \prime}(0)$ from the known condition $f^{\prime}(\infty)=1$. By knowing the value of $f^{\prime \prime}(0)$, Blasius problem can be solved as an IVP. The derivation of an expression for $f^{\prime \prime}(0)$ is reviewed here by considering a function $g$ with

$$
\begin{aligned}
& g^{\prime \prime \prime}+\frac{1}{2} g g^{\prime \prime}=0, \quad \text { with } \\
& \quad g(0)=g^{\prime}(0)=0 \text { and } g^{\prime \prime}(0)=1
\end{aligned}
$$

By scaled symmetry, the solution of $g$ and $f$ are related by the scaling relation

$$
\begin{gathered}
f(\eta)=a g(a \eta) \quad \text { By differentiating, } \\
\text { we can write } f^{\prime}(\eta)=a^{2} g^{\prime}(a \eta) \\
\Rightarrow f^{\prime}(\infty)=a^{2} g^{\prime}(\infty) \\
\Rightarrow g^{\prime}(\infty)=\frac{f^{\prime}(\infty)}{a^{2}}=\frac{1}{a^{2}} \\
\Rightarrow a=\left[g^{\prime}(\infty)\right]^{-1 / 2} \\
f^{\prime \prime}(\eta)=a^{3} g^{\prime \prime}(a \eta)
\end{gathered}
$$

$$
\Rightarrow f^{\prime \prime}(0)=a^{3} g^{\prime \prime}(0)=a^{3}=\left[g^{\prime}(\infty)\right]^{-3 / 2}
$$

The value of $g^{\prime}(\infty)$ is to be first determined by solving the IVP of $g$ in Eq. (12). By finding $f^{\prime \prime}(0)=$ $\left[g^{\prime}(\infty)\right]^{-3 / 2}$, the Blasius problem can be solved as an IVP.

\subsection{Solution of IVP}

Initial value problems can be solved either numerically or analytically. Blasius IVP has been numerically solved by applying Runge-Kutta method in (K.Toepfer and H.Blasius. (1912), Howarth (1938), Cortell (2005), Boyd (2008), Zaimi, Bidin, Bakar, and Hamid (2012)). Taylor's series method has been used to analytically solve different types of IVPs in (Ganji, Babazadeh, Noori, Pirouz, and Janipour (2009), Asaithambi (2005)). In Taylor's series method, the differential equation is successively differentiated to find higher order derivatives from the known values of lower order derivatives. The series may be a terminating or a nonterminating one, depending on whether the derivatives vanish or not beyond a particular order derivative. A difficulty with non-terminating series is 
from its divergence behavior, when the function contains singularities. The radius of convergence of series expansion of a function with singularities is the distance between the center of expansion and its closest singularity. It is possible to change the radius of convergence by changing the center of expansion. A systematic approach for obtaining the Taylor's series solution of IVPs, is first developed by Zhou (1986), called differential transform method. A review of this method and its application for determining the value of $f^{\prime \prime}(0)$ with the help of the solution of IVP in Eq.(12) are given in the following.

\subsubsection{Method of differential transform}

The Taylor's expansion of a function $g(\eta)$ about $\eta=\eta_{i}$ is

$$
\begin{aligned}
& g(\eta)=g\left(\eta_{i}\right)+\sum_{k=1}^{\infty} \frac{1}{k !}\left[g^{k}(\eta)\right]_{\eta=\eta_{i}}\left(\eta-\eta_{i}\right)^{k} \\
& =G(0)+\sum_{k=1}^{\infty} G(k)\left(\eta-\eta_{i}\right)^{k}
\end{aligned}
$$

Where $G(k)=\frac{1}{k !}\left[g^{k}(\eta)\right]_{\eta=\eta_{i}}$ for $k>0 . G(k)$ denotes the coefficient of $k^{\text {th }}$ degree term of Taylor's series expansion of $g\left(\eta\right.$ and $G(0)=g\left(\eta_{i}\right)$. Zhou (1986) considered $G(k)$ as a transform of $g(\eta)$ called differential transform. Since then several useful properties of the differential transform were studied (Arikoglu and Ozkol (2005), Bildik and Konuralp (2011), Arikoglu and Ozkol (2008)). These properties have been useful for the solution of IVPs. The differential transform of a derivative $g(\eta)$ is obtained by differentiating Eq. (14)

$$
\begin{gathered}
g^{\prime}(\eta)=\sum_{k=1}^{\infty} G(k) k\left(\eta-\eta_{i}\right)^{k-1} \\
\text { taking } p=k-1 \\
=\sum_{p=0}^{\infty} G(p+1)(p+1)\left(\eta-\eta_{i}\right)^{p} \\
=\sum_{k=0}^{\infty} G(k+1)(k+1)\left(\eta-\eta_{i}\right)^{k} \\
=\sum_{k=0}^{\infty} G_{1}(k)\left(\eta-\eta_{i}\right)^{k}
\end{gathered}
$$

where $G_{1}(k)=(k+1) G(k+1)$ is the differential transform of the first derivative of $g(\eta)$. In this manner the differential transform of the $m^{\text {th }}$ derivative of $g(\eta)$ is

$$
G_{m}(k)=(k+1)(k+2) \ldots(k+m) G(k+m)
$$

$\Rightarrow G(k+m)=\frac{k !}{(k+m) !} G_{m}(k)$

This gives a recurrence relation for the successive differential transforms of $g(\eta)$.

The differential transform of the product term in the governing Eq. (12), viz. $g(\eta) g^{\prime \prime}(\eta)$ is denoted as $G G_{2}(k)$ and is obtained using Leibnitz rule as in the following.

$$
G G_{2}(k)=\frac{1}{k !} \frac{d^{k}}{d \eta^{k}}\left[g(\eta) g^{\prime \prime}(\eta)\right]
$$

Expanding $n^{\text {th }}$ differential of product using Leibnitz rule,

$$
\begin{gathered}
G G_{2}(k)=\frac{1}{k !} \sum_{i=0}^{k}(k i) \frac{d^{i} g(\eta)}{d \eta^{i}} \frac{d^{k-i} g^{\prime \prime}(\eta)}{d \eta^{k-1}} \\
=\frac{1}{k !} \sum_{i=0}^{k}\left(\begin{array}{c}
k \\
i
\end{array}\right) i ! G(i)(k-i) ! G_{2}(k-i)
\end{gathered}
$$

$\Rightarrow G G_{2}(k)=\sum_{i=0}^{k} G(i) G_{2}(k-i)$

By knowing $G(0)=0, G^{\prime}(0)=0$ and $G^{\prime \prime}(0)=1$, the recurrence relations for computing the differential transform of $g(\eta)$ for any value of $k$ are summarized as

$$
G(k+1)=\frac{G_{1}(k)}{k+1} ; \quad G_{1}(k+1)=\frac{G_{2}(k)}{k+1} \text { and }
$$

$$
G_{2}(k+1)=-\frac{1}{2(k+1)} \sum_{i=0}^{k} G(k) G_{2}(k-i)
$$

$G(k)$ is computed up to the required number of terms $(k)$ of the series. By knowing $G(k)$, the power series for $g(\eta)$ is obtained as in Eq. (14)

\subsubsection{Determination of initial value of $f^{\prime \prime}(\eta)$}

Firstly, we studied the convergence property of the series obtained for $g(\eta)$ by keeping $k$ arbitrarily equal to 1000 . It is found that the series of $g(\eta)$ expanded with $\eta_{i}=0$ as the center of the expansion starts to diverge for $\eta>3.8$. So it is inferred that the function $g(\eta)$ has singularity at $\eta<-3.8$. Due to this singularity, we have restricted the computation of $g(\eta)$ using this series for $\triangle \eta<3$.8. By treating the value of $g(\eta), g^{\prime}(\eta)$ and $g^{\prime \prime}(\eta)$ obtained from this series at $\eta=\triangle \eta$ as the initial value, a second series is computed for $\triangle \eta<\eta<2 \Delta \eta$. In this manner a required number of split series have been 
computed for equal intervals of $\eta, \triangle \eta=1$ up to a maximum value of $\eta, \eta_{m}=15$. The value of $g^{\prime}(15)$ computed from the last series is taken as $g^{\prime}(\infty)$ and hence $f^{\prime \prime}(0)=\left[g^{\prime}\left(\eta_{m}=15\right)\right]^{-3 / 2}$ is computed. The result obtained from the present extended double precision computation with 21 decimal digits accuracy and using a total of 40 terms in each series is

\section{$f^{\prime \prime}(0)=0.332057336215196299183$}

The above value is found to be invariant for $\eta_{m}>15$ and $k>40$. The result matches exactly with the value reported by Boyd (1999), which is found numerically using Runge-Kutta method, 27 decimal place accuracy computations and 50,000 grid points. While the computational effort involved in the present solution is much less, it confirms that the results Boyd (1999) believes as correct is correct. However the result obtained in the present work is more accurate than already reported values.

\section{Solution OF BLASIUS FUnCtion}

With the result for $f^{\prime \prime}(0)$ obtained above, the Blasius function defined defined by $f^{\prime \prime \prime}+\frac{1}{2} f f^{\prime \prime}=0$ with $f(0)=f^{\prime}(0)=0$ becomes an initial value problem and is solved by computing $F(k)$ using the recursive relations in Eq.(18) by changing $G$ to $F$ and $F(0)=F_{1}(0)=0$ and $F_{2}(0)=$ 0.332057336215196299183 . The series thus obtained is the Taylor's series expansion about $\eta=0$ and is found to diverge for $\eta>5.69$ due to the singularity of $f(\eta)$ at $\eta=-5.69$, Boyd (1999). Hence the series obtained is used to compute the values of $f(4)=2.30574641846207118020$, $f^{\prime}(4)=0.955518229810694247274$ and $f^{\prime \prime}(4)=$ $6.42341210916906681680 E-0002$. Using these values as initial values at $\eta=4$, another series for $f(\eta)$ is computed with the center of expansion at $\eta=4$. The series is an alternating one. Computation of the function by summing finite number of terms of the series expanded about $\eta=4$ shows that, accurate result is obtained in $0 \leq \eta \leq 8$, for summation with only 200 terms. But the results obtained by summing 200 terms of the series is found to give unrealistic values for $\eta>8$. By increasing the number of terms of summation to 2000, the same series is found to give accurate results up to $\eta=9$. The values of the function and its derivatives obtained in the present work are tabulated in Table 1 . The variation of $f^{\prime}(\eta)$ and $f^{\prime \prime}(\eta)$ thus obtained are depicted in Fig. 3. The first 200 coefficients of series are given in Table 2 . We expect that the present Taylor series expansion about $\eta=4$ is more accurate than any other results reported in literature. At $\eta=9$, the solution is close to asymptotic variation with the value of $f^{\prime}(\eta)$ being nearly constant with changes only after 7 decimal places.

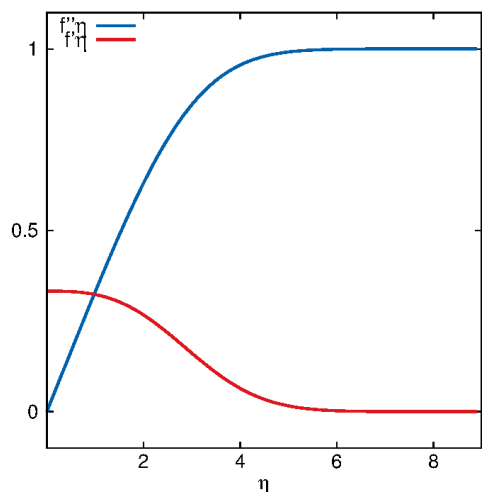

Fig. 3. Variation of $f^{\prime}(\eta)$ and $f^{\prime \prime}(\eta)$ with respect to $\eta$.

We also investigated the asymptotic parameters using successive series constructed up to $\eta=20$ and the asymptotic variation is obtained as

$$
\begin{aligned}
f(\eta) & =\eta+B \quad \text { and } \\
f^{\prime \prime}(\eta) & =Q \exp \left(-\frac{1}{4} \eta(\eta+2 B)\right)
\end{aligned}
$$

where the obtained values of $B$ and $Q \quad$ are $\quad-1.72078765752050281274$ and 0.1114837549978888824 respectively. The present value of $B$ is found to match with a better accuracy with the results presented in Boyd (2008) of -1.720787657520503 . However, the value of $Q$ obtained is different from the one reported in Boyd (2008) of 0.233727621285063 . The results reported in this paper is after a through verification only.

\section{Conclusions}

The method of differential transforms has been applied to generate the Taylor's series expansion of the Blasius function, $f(\eta)$. The paper reports a methodology involving recursive application of differential transform method for shifting the center of expansion of functions expressed in the form of differential equations. The series for Blasius function has been expanded about $\eta=4$, which provided a higher radius of convergence in the positive range of $\eta$. The series is alternating and the accuracy of the evaluated function is found to depend on the number of terms summed for $\eta>4$. The series reported is convergent for $\eta \in[0,9]$ when 2000 are used for summation. A 21 decimal places accurate value of the second derivative of the function at $\eta=0$, which physically represents the shear stress on the surface of the plate is 0.332057336215196299183 . The parameters of the asymptotic solution is also obtained with a 21 decimal places accuracy. 
S.Anil Lal et al. / JAFM, Vol. 7, No. 4, pp. 557-564, 2014.

Table 1 Tabulated values of $f(\eta), f^{\prime}(\eta), f^{\prime \prime}(\eta)$ obtained with Taylor's series expansion about $\eta=4$

\begin{tabular}{|c|c|c|c|}
\hline$\eta$ & $f(\eta)$ & $f^{\prime}(\eta)$ & $f^{\prime \prime}(\eta)$ \\
\hline 0 & $-2.90451215935441549708 \mathrm{E}-0019$ & $2.92231574613161685905 \mathrm{E}-0019$ & 0.332057336215196 \\
\hline 0.2 & $6.64099971459704033365 \mathrm{E}-0003$ & $6.64077920962507645673 \mathrm{E}-0002$ & 0.331983837114628 \\
\hline 0.4 & $2.65598840179947234234 \mathrm{E}-0002$ & 0.132764160761022 & 0.331469844201455 \\
\hline 0.6 & $5.97346374980383965769 \mathrm{E}-0002$ & 0.198937252422219 & 0.330079127574296 \\
\hline 0.8 & 0.106108220839041 & 0.264709138723117 & 0.327389270149252 \\
\hline 1 & 0.165571725789280 & 0.329780031249667 & 0.323007116686943 \\
\hline 1.2 & 0.237948717288927 & 0.393776104433956 & 0.316589191061116 \\
\hline 1.4 & 0.322981573829535 & 0.456261764705134 & 0.307865391790168 \\
\hline 1.6 & 0.420320765501626 & 0.516756784422615 & 0.296663461455719 \\
\hline 1.8 & 0.529518037743810 & 0.574758143889457 & 0.282931017259756 \\
\hline 2 & 0.650024369935289 & 0.629765736502386 & 0.266751545697278 \\
\hline 2.2 & 0.781193337010573 & 0.681310377236027 & 0.248350913190371 \\
\hline 2.4 & 0.922290125634541 & 0.728981935062575 & 0.228091760686684 \\
\hline 2.6 & 1.072505976787830 & 0.772455021148565 & 0.206454626799426 \\
\hline 2.8 & 1.230977302314310 & 0.811509623199109 & 0.184006593865361 \\
\hline 3 & 1.396808230870350 & 0.846044443657994 & 0.161360319540879 \\
\hline 3.2 & 1.569094960006760 & 0.876081455172477 & 0.139128055572426 \\
\hline 3.4 & 1.746950093948840 & 0.901761221436765 & 0.117876246087524 \\
\hline 3.6 & 1.929525169760530 & 0.923329665881649 & $9.80862787842802132048 \mathrm{E}-0002$ \\
\hline 3.8 & 2.116029817172070 & 0.941117996729313 & $8.01259181391971851178 \mathrm{E}-0002$ \\
\hline 4 & 2.305746418462070 & 0.955518229810694 & $6.42341210916906681680 \mathrm{E}-0002$ \\
\hline 4.2 & 2.498039662706970 & 0.966957073753606 & $5.05197474866457608118 \mathrm{E}-0002$ \\
\hline 4.4 & 2.692360937543090 & 0.975870832136478 & $3.89726108536295503280 \mathrm{E}-0002$ \\
\hline 4.6 & 2.888247990017810 & 0.982683500760700 & $2.94837720116487089967 \mathrm{E}-0002$ \\
\hline 4.8 & 3.085320655177480 & 0.987789526200787 & $2.18711863474432831236 \mathrm{E}-0002$ \\
\hline 5 & 3.283273665156310 & 0.991541900164393 & $1.59067986853181631358 \mathrm{E}-0002$ \\
\hline 5.2 & 3.481867611508660 & 0.994245535359928 & $1.13417889689291312873 \mathrm{E}-0002$ \\
\hline 5.4 & 3.680919062897510 & 0.996155303962753 & $7.92765981470613569935 \mathrm{E}-0003$ \\
\hline 5.6 & 3.880290677633380 & 0.997477768212915 & $5.43195767992749243316 \mathrm{E}-0003$ \\
\hline 5.8 & 4.079881939239700 & 0.998375493650191 & $3.64841366674732585084 \mathrm{E}-0003$ \\
\hline 6 & 4.279620922513850 & 0.998972872435860 & $2.40203984375727885487 \mathrm{E}-0003$ \\
\hline 6.2 & 4.479457297282690 & 0.999362541719091 & $1.55017069065636743797 \mathrm{E}-0003$ \\
\hline 6.4 & 4.679356615431430 & 0.999611701717676 & $9.80615117009763015151 \mathrm{E}-0004$ \\
\hline 6.6 & 4.879295811060250 & 0.999767870210032 & $6.08044264784485316850 \mathrm{E}-0004$ \\
\hline 6.8 & 5.079259772449010 & 0.999863819037038 & $3.69562570140311736630 \mathrm{E}-0004$ \\
\hline 7 & 5.279238811029110 & 0.999921604147950 & $2.20168955271134609014 \mathrm{E}-0004$ \\
\hline 7.2 & 5.479226847343180 & 0.999955717277927 & $1.28569807235158993429 \mathrm{E}-0004$ \\
\hline 7.4 & 5.679220147333840 & 0.999975457684898 & $7.35929833892270373715 \mathrm{E}-0005$ \\
\hline 7.6 & 5.879216465804060 & 0.999986655139129 & $4.12903111137017749811 \mathrm{E}-0005$ \\
\hline 7.8 & 6.079214481071950 & 0.999992881166101 & $2.27077514028069458891 \mathrm{E}-0005$ \\
\hline 8 & 6.279213431346080 & 0.999996274535301 & $1.22409262432531429552 \mathrm{E}-0005$ \\
\hline 8.2 & 6.479212886678500 & 0.999998087459238 & $6.46797861084886973152 \mathrm{E}-0006$ \\
\hline 8.4 & 6.679212609441440 & 0.999999036874844 & $3.34993975319999345318 \mathrm{E}-0006$ \\
\hline 8.6 & 6.879212471015070 & 0.999999524247805 & $1.70066798857665268096 \mathrm{E}-0006$ \\
\hline 8.8 & 7.079212403216730 & 0.999999769489751 & $8.46284121306853119521 \mathrm{E}-0007$ \\
\hline 9 & 7.279212370645330 & 0.999999890444161 & $3.92686164651959923121 \mathrm{E}-0007$ \\
\hline
\end{tabular}


S.Anil Lal et al. / JAFM, Vol. 7, No. 4, pp. 557-564, 2014.

Table 2 First 200 coefficients of the Taylor series expansion of the Blasius function given by $f(\eta)=$ $\sum_{k=0} F(k)(\eta-4)^{k}$.

\begin{tabular}{|c|c|c|c|c|c|}
\hline$k$ & $F(k)$ & $k$ & $F(k)$ & $k$ & $F(k)$ \\
\hline 0 & 2.305746418462070 & 67 & $1.54501387536272496428 \mathrm{E}-0047$ & 134 & $3.32266142258623029852 \mathrm{E}-0095$ \\
\hline 1 & 0.955518229810694 & 68 & $-5.31812426339887940710 \mathrm{E}-0049$ & 135 & $-1.98310538234261656202 \mathrm{E}-0095$ \\
\hline 2 & $3.21170605458453340840 \mathrm{E}-0002$ & 69 & $-5.55103174036789546845 \mathrm{E}-0049$ & 136 & $4.91278759876207123111 \mathrm{E}-0097$ \\
\hline 3 & $-1.23422995541853953195 \mathrm{E}-0002$ & 70 & $7.08312566937082614087 \mathrm{E}-0050$ & 137 & $7.29857631119625434430 \mathrm{E}-0097$ \\
\hline 4 & $2.27859175576908150426 \mathrm{E}-0003$ & 71 & $1.52787645522513563236 \mathrm{E}-0050$ & 138 & $-8.49971735072191697622 \mathrm{E}-0098$ \\
\hline 5 & $4.70873734551596933229 \mathrm{E}-0005$ & 72 & $-4.14304257606461522218 \mathrm{E}-0051$ & 139 & $-2.08270073195395656503 \mathrm{E}-0098$ \\
\hline 6 & $-1.04696147203046357531 \mathrm{E}-0004$ & 73 & $-2.22689450789485071198 \mathrm{E}-0052$ & 140 & $5.19628448478923655496 \mathrm{E}-0099$ \\
\hline 7 & $1.04849728513766856216 \mathrm{E}-0005$ & 74 & $1.81809909360485798211 \mathrm{E}-0052$ & 141 & $3.44441060727620368746 \mathrm{E}-0100$ \\
\hline 8 & $3.65883591635046807686 \mathrm{E}-0006$ & 75 & $-7.70672457610464815904 \mathrm{E}-0054$ & 142 & $-2.33913302679774233968 \mathrm{E}-0100$ \\
\hline 9 & $-8.26198757173262535534 \mathrm{E}-0007$ & 76 & $-6.40184069216592913088 \mathrm{E}-0054$ & 143 & $7.64798370293702712169 \mathrm{E}-0102$ \\
\hline 10 & $-8.56871408032604090498 \mathrm{E}-0008$ & 77 & $8.78278560115632077167 \mathrm{E}-0055$ & 144 & $8.44177733364167930062 \mathrm{E}-0102$ \\
\hline 11 & $4.24206814475960916804 \mathrm{E}-0008$ & 78 & $1.70679514631881930489 \mathrm{E}-0055$ & 145 & $-1.05983538572098169671 \mathrm{E}-0102$ \\
\hline 12 & $1.24757464648407639619 \mathrm{E}-0010$ & 79 & $-4.96792309934810891449 \mathrm{E}-0056$ & 146 & $-2.33973464442283964453 \mathrm{E}-0103$ \\
\hline 13 & $-1.73812386504572966263 \mathrm{E}-0009$ & 80 & $-2.18166098174541908883 \mathrm{E}-0057$ & 147 & $6.24732251568732334987 \mathrm{E}-0104$ \\
\hline 14 & $1.32651440735246801945 \mathrm{E}-0010$ & 81 & $2.13605639450487796055 \mathrm{E}-0057$ & 148 & $3.50003576896367677002 \mathrm{E}-0105$ \\
\hline 15 & $5.77723961725846969334 \mathrm{E}-0011$ & 82 & $-1.07501564878974550764 \mathrm{E}-0058$ & 149 & $-2.75444920540216826285 \mathrm{E}-0105$ \\
\hline 16 & $-9.81264996803191772378 \mathrm{E}-0012$ & 83 & $-7.36873048290769883333 \mathrm{E}-0059$ & 150 & $1.11759533406814347334 \mathrm{E}-0106$ \\
\hline 17 & $-1.41677737579443119458 \mathrm{E}-0012$ & 84 & $1.08427286052096212108 \mathrm{E}-0059$ & 151 & $9.74493755794952565242 \mathrm{E}-0107$ \\
\hline 18 & $4.94795732662933281514 \mathrm{E}-0013$ & 85 & $1.89852773644347656379 \mathrm{E}-0060$ & 152 & $-1.31507152738594442086 \mathrm{E}-0107$ \\
\hline 19 & $1.17217679853551754637 \mathrm{E}-0014$ & 86 & $-5.94498871412526580801 \mathrm{E}-0061$ & 153 & $-2.61829774025888477805 \mathrm{E}-0108$ \\
\hline 20 & $-1.99587570380654368497 \mathrm{E}-0014$ & 87 & $-2.04918333875349427543 \mathrm{E}-0062$ & 154 & $7.49489815935327201785 \mathrm{E}-0109$ \\
\hline 21 & $1.32173139876612546061 \mathrm{E}-0015$ & 88 & $2.50554860386806934685 \mathrm{E}-0062$ & 155 & $3.46247610727717591164 \mathrm{E}-0110$ \\
\hline 22 & $6.50222871563387972142 \mathrm{E}-0016$ & 89 & $-1.45989473509745392038 \mathrm{E}-0063$ & 156 & $-3.23808598353568341220 \mathrm{E}-0110$ \\
\hline 23 & $-1.09893230989100695430 \mathrm{E}-0016$ & 90 & $-8.46414930933756714068 \mathrm{E}-0064$ & 157 & $1.56837815247303581412 \mathrm{E}-0111$ \\
\hline 24 & $-1.52737229367497166915 \mathrm{E}-0017$ & 91 & $1.33329661960224071757 \mathrm{E}-0064$ & 158 & $1.12264456091526251036 \mathrm{E}-0111$ \\
\hline 25 & $5.66376444706610288373 \mathrm{E}-0018$ & 92 & $2.10162418626519246400 \mathrm{E}-0065$ & 159 & $-1.62464168640150274164 \mathrm{E}-0112$ \\
\hline 26 & $8.23901176700155878733 \mathrm{E}-0020$ & 93 & $-7.10027168819215405316 \mathrm{E}-0066$ & 160 & $-2.91748745259002246431 \mathrm{E}-0113$ \\
\hline 27 & $-2.28577360586863227790 \mathrm{E}-0019$ & 94 & $-1.80033565851515105991 \mathrm{E}-0067$ & 161 & $8.97318111790271961126 \mathrm{E}-0114$ \\
\hline 28 & $1.74072742066617737900 \mathrm{E}-0020$ & 95 & $2.93411471403056952770 \mathrm{E}-0067$ & 162 & $3.29739576663407194330 \mathrm{E}-0115$ \\
\hline 29 & $7.35859232836632572406 \mathrm{E}-0021$ & 96 & $-1.94347659185749439227 \mathrm{E}-0068$ & 163 & $-3.80028614160509840123 \mathrm{E}-0115$ \\
\hline 30 & $-1.34125625738890900092 \mathrm{E}-0021$ & 97 & $-9.70115483508269533097 \mathrm{E}-0069$ & 164 & $2.13978710831118307653 \mathrm{E}-0116$ \\
\hline 31 & $-1.66576227379246042319 \mathrm{E}-0022$ & 98 & $1.63361932786724523668 \mathrm{E}-0069$ & 165 & $1.29058709364809346050 \mathrm{E}-0116$ \\
\hline 32 & $6.72719348653922713935 \mathrm{E}-0023$ & 99 & $2.31372729996307639952 \mathrm{E}-0070$ & 166 & $-1.99914874450570455454 \mathrm{E}-0117$ \\
\hline 33 & $4.47986953506900797484 \mathrm{E}-0025$ & 100 & $-8.46393064540148693651 \mathrm{E}-0071$ & 167 & $-3.23538207487299957791 \mathrm{E}-0118$ \\
\hline 34 & $-2.66217397630806611422 \mathrm{E}-0024$ & 101 & $-1.39872542971117784716 \mathrm{E}-0072$ & 168 & $1.07218295353518230320 \mathrm{E}-0118$ \\
\hline 35 & $2.22094716106009716605 \mathrm{E}-0025$ & 102 & $3.43024735807583352017 \mathrm{E}-0072$ & 169 & $2.96153117239146438211 \mathrm{E}-0120$ \\
\hline 36 & $8.37518589248022676550 \mathrm{E}-0026$ & 103 & $-2.54762577587736166286 \mathrm{E}-0073$ & 170 & $-4.45262995301557455429 \mathrm{E}-0120$ \\
\hline 37 & $-1.62032325216119842570 \mathrm{E}-0026$ & 104 & $-1.10931882405391600733 \mathrm{E}-0073$ & 171 & $2.85915374479122709354 \mathrm{E}-0121$ \\
\hline 38 & $-1.80417114775513806918 \mathrm{E}-0027$ & 105 & $1.99498870478017624911 \mathrm{E}-0074$ & 172 & $1.48037738674014021808 \mathrm{E}-0121$ \\
\hline 39 & $7.94497605733967138028 \mathrm{E}-0028$ & 106 & $2.53129553760214968666 \mathrm{E}-0075$ & 173 & $-2.45111629181960645349 \mathrm{E}-0122$ \\
\hline 40 & $-1.31123133608615312516 \mathrm{E}-0030$ & 107 & $-1.00708268177728895733 \mathrm{E}-0075$ & 174 & $-3.56871470585556566006 \mathrm{E}-0123$ \\
\hline 41 & $-3.08709986811484909863 \mathrm{E}-0029$ & 108 & $-7.99094501758040271974 \mathrm{E}-0078$ & 175 & $1.27867865023698921137 \mathrm{E}-0123$ \\
\hline 42 & $2.83643551339292736220 \mathrm{E}-0030$ & 109 & $4.00347533206144321137 \mathrm{E}-0077$ & 176 & $2.40069995010899130421 \mathrm{E}-0125$ \\
\hline 43 & $9.48498873147394786300 \mathrm{E}-0031$ & 110 & $-3.29860210791528839734 \mathrm{E}-0078$ & 177 & $-5.20816657462216582648 \mathrm{E}-0125$ \\
\hline 44 & $-1.96239700983573131081 \mathrm{E}-0031$ & 111 & $-1.26537714511528773244 \mathrm{E}-0078$ & 178 & $3.75939661400478264250 \mathrm{E}-0126$ \\
\hline 45 & $-1.93062640742544893606 \mathrm{E}-0032$ & 112 & $2.42887538378505860767 \mathrm{E}-0079$ & 179 & $1.69414107846743310407 \mathrm{E}-0126$ \\
\hline 46 & $9.39884978039657251875 \mathrm{E}-0033$ & 113 & $2.74926501369107772531 \mathrm{E}-0080$ & 180 & $-2.99531171891903060726 \mathrm{E}-0127$ \\
\hline 47 & $-9.44658358717036897237 \mathrm{E}-0035$ & 114 & $-1.19611735377873318470 \mathrm{E}-0080$ & 181 & $-3.91246681071946192982 \mathrm{E}-0128$ \\
\hline 48 & $-3.58235244301780394135 \mathrm{E}-0034$ & 115 & $5.45848162805759581119 \mathrm{E}-0084$ & 182 & $1.52211748212612817695 \mathrm{E}-0128$ \\
\hline 49 & $3.59998116828591784697 \mathrm{E}-0035$ & 116 & $4.66444522909785624503 \mathrm{E}-0082$ & 183 & $1.54740743786132968865 \mathrm{E}-0130$ \\
\hline 50 & $1.07319195469366880764 \mathrm{E}-0035$ & 117 & $-4.22787751275740452986 \mathrm{E}-0083$ & 184 & $-6.08154750822682764854 \mathrm{E}-0130$ \\
\hline 51 & $-2.37289361171275313764 \mathrm{E}-0036$ & 118 & $-1.43960886734871669480 \mathrm{E}-0083$ & 185 & $4.88007598324053527639 \mathrm{E}-0131$ \\
\hline 52 & $-2.04749652874355638181 \mathrm{E}-0037$ & 119 & $2.94875414605123670983 \mathrm{E}-0084$ & 186 & $1.93403040466493136928 \mathrm{E}-0131$ \\
\hline 53 & $1.11071547179463322454 \mathrm{E}-0037$ & 120 & $2.96063239108923121816 \mathrm{E}-0085$ & 187 & $-3.64911916541314266416 \mathrm{E}-0132$ \\
\hline 54 & $-2.02932330331279453972 \mathrm{E}-0039$ & 121 & $-1.41812584925099760909 \mathrm{E}-0085$ & 188 & $-4.25936402268573012745 \mathrm{E}-0133$ \\
\hline 55 & $-4.15165949145151586119 \mathrm{E}-0039$ & 122 & $1.23138976698643687366 \mathrm{E}-0087$ & 189 & $1.80862982435781603856 \mathrm{E}-0133$ \\
\hline 56 & $4.53729073624533658245 \mathrm{E}-0040$ & 123 & $5.42499798635919130266 \mathrm{E}-0087$ & 190 & $3.17975556085456888547 \mathrm{E}-0136$ \\
\hline 57 & $1.21099631862884071177 \mathrm{E}-0040$ & 124 & $-5.37309525832258432683 \mathrm{E}-0088$ & 191 & $-7.08915855474350595345 \mathrm{E}-0135$ \\
\hline 58 & $-2.86332220243352692683 \mathrm{E}-0041$ & 125 & $-1.63324208515998331941 \mathrm{E}-0088$ & 192 & $6.26863364229039895060 \mathrm{E}-0136$ \\
\hline 59 & $-2.14341684396764355044 \mathrm{E}-0042$ & 126 & $3.57042744191734994042 \mathrm{E}-0089$ & 193 & $2.20216391074229466648 \mathrm{E}-0136$ \\
\hline 60 & $1.31092098910088389845 \mathrm{E}-0042$ & 127 & $3.15594254328568438522 \mathrm{E}-0090$ & 194 & $-4.43296914517726799461 \mathrm{E}-0137$ \\
\hline 61 & $-3.45994909030007761337 \mathrm{E}-0044$ & 128 & $-1.67842448710311967717 \mathrm{E}-0090$ & 195 & $-4.59925337912476525914 \mathrm{E}-0138$ \\
\hline 62 & $-4.80456683832639116100 \mathrm{E}-0044$ & 129 & $2.81616923412489590751 \mathrm{E}-0092$ & 196 & $2.14527570427798719383 \mathrm{E}-0138$ \\
\hline 63 & $5.68461628720700586137 \mathrm{E}-0045$ & 130 & $6.29823623471267266357 \mathrm{E}-0092$ & 197 & $-1.39089427591724692783 \mathrm{E}-0140$ \\
\hline 64 & $1.36252363156128811891 \mathrm{E}-0045$ & 131 & $-6.77919326752912501650 \mathrm{E}-0093$ & 198 & $-8.24924536692309434289 \mathrm{E}-0140$ \\
\hline 65 & $-3.44793820089044350070 \mathrm{E}-0046$ & 132 & $-1.84733958285133870664 \mathrm{E}-0093$ & 199 & $7.98184787277333689447 \mathrm{E}-0141$ \\
\hline 66 & $-2.20803805096678201288 \mathrm{E}-0047$ & 133 & $4.31239629098361091948 \mathrm{E}-0094$ & & \\
\hline
\end{tabular}




\section{REFERENCES}

Arikoglu, A. and I. Ozkol (2005). Solution of boundary value problems for integro-differential equations by using differential transform method. Applied Mathematics and Computation 168(2), 1145-1158.

Arikoglu, A. and I. Ozkol (2008). Solutions of integral and integro-differential equation systems by using differential transform method. Computers \& Mathematics with Applications 56(9), 24112417.

Asaithambi, A. (2005). Solution of the falknerskan equation by recursive evaluation of taylor coefficients. Journal of Computational and Applied Mathematics 176(1), 203-214.

Bildik, N. and A. Konuralp (2011). The use of variational iteration method, differential transform method and adomian decomposition method for solving different types of nonlinear partial differential equations. International Journal of Nonlinear Sciences and Numerical Simulation 7(1), 65-70.

Blasius, H. (1908). Grenzschichten in flussigkeiten mit kleiner reibung. Z. Math Phys., 56:137.

Boyd, J. (1999). The blasius function in the complex plane. Experimental Mathematics 8(4), 381-394.

Boyd, J. (2008). The blasius function: computations before computers, the value of tricks, un- dergraduate projects, and open research problems. SIAM review 50(4), 791-804.

Cengel, Y. A. (2006). Heat and mass transfer: A practical approach (si units).

Cortell, R. (2005). Numerical solutions of the classical blasius flat-plate problem. Applied mathematics and computation 170(1), 706-710.

Ganji, D., H. Babazadeh, F. Noori, M. Pirouz, and M. Janipour (2009). An application of homotopy perturbation method for non-linear blasius equation to boundary layer flow over a flat plate. International Journal of Nonlinear Science 7(4), 399-404.

Howarth, L. (1938). On the solution of the laminar boundary layer equations. Proc London Math Soc A, 164:54779.

K.Toepfer and H.Blasius. (1912). Grenzschichten in flussigkeiten mit kleiner reibung. $Z$. Math Phys.(1912).

Zaimi, W., B. Bidin, N. Bakar, and R. Hamid (2012). Applications of runge-kutta-fehlberg method and shooting technique for solving classical blasius equation. World Applied Sciences Journal 17 (Special Issue of Applied Math), 10-15.

Zhou, J. (1986). Differential transformation and its applications for electrical circuits. 